\title{
Identification of biomarkers for the antiangiogenic and antitumour activity of the superoxide dismutase I (SODI) inhibitor tetrathiomolybdate (ATN-224)
}

\author{
F Doñate*,', JC Juarez', ME Burnett', MM Manuia', X Guan', DE Shaw ${ }^{2}$, ELP Smith ${ }^{3}$, C Timucin ${ }^{3}$, \\ MJ Braunstein ${ }^{3}$, OA Batuman ${ }^{3}$ and AP Mazar' \\ 'Attenuon, LLC, San Diego, CA 92121 , USA; ${ }^{2}$ DE Shaw Research, LLC, New York, NY 10036, USA; ${ }^{3}$ Division of Hematology and Oncology, State \\ University of New York, Downstate Medical Center, Brooklyn, NY I I 203, USA
}

\begin{abstract}
Tetrathiomolybdate (choline salt; ATN-224), a specific, high-affinity copper binder, is currently being evaluated in several phase II cancer trials. ATN-224 inhibits CuZn superoxide dismutase I (SODI) leading to antiangiogenic and antitumour effects. The pharmacodynamics of tetrathiomolybdate has been followed by tracking ceruloplasmin (Cp), a biomarker for systemic copper. However, at least in mice, the inhibition of angiogenesis occurs before a measurable decrease in systemic copper is observed. Thus, the identification and characterisation of other biomarkers to follow the activity of ATN-224 in the clinic is of great interest. Here, we present the preclinical evaluation of two potential biomarkers for the activity of ATN-224: (i) SOD activity measurements in blood cells in mice and (ii) levels of endothelial progenitor cells (EPCs) in bonnet macaques treated with ATN-224. The superoxide dismutase activity in blood cells in mice is rapidly inhibited by ATN-224 treatment at doses at which angiogenesis is maximally inhibited. Furthermore, ATN-224 dosing in bonnet macaques causes a profound and reversible decrease in EPCs without significant toxicity. Thus, both SOD activity measurements and levels of EPCs may be useful biomarkers of the antiangiogenic activity of ATN-224 to be used in its clinical development.
\end{abstract}

British Journal of Cancer (2008) 98, 776-783. doi:10.1038/sj.bjc.6604226 www.bjcancer.com

Published online 5 February 2008

(c) 2008 Cancer Research UK

Keywords: biomarkers; angiogenesis; superoxide dismutase; tetrathiomolybdate; circulating progenitor cells

Angiogenesis, the process of formation of new blood vessels from pre-existing ones, is critical for tumour growth and a promising therapeutic target for the treatment of cancer (Carmeliet, 2005; Doñate, 2005; Ferrara and Kerbel, 2005). Tetrathiomolybdate (TM) is an orally available copper-binding compound that has been shown to have efficacy as an antiangiogenic and antitumour agent in several mouse models of cancer (Pan et al, 2002, 2003a, b; Lowndes and Harris, 2004; Goodman et al, 2005; Hassouneh et al, 2007), and has also been tested as an anticancer therapy in several clinical trials (Brewer et al, 2000; Redman et al, 2003). The ability of TM to inhibit angiogenesis has been attributed to the depletion of systemic copper, which has been described to affect multiple key regulators of angiogenesis (Brewer et al, 2000; Pan et al, 2002, 2003a,b; Redman et al, 2003; Goodman et al, 2005; Hassouneh et al, 2007). ATN-224 is a second-generation choline salt of TM with improved stability, which has been tested in two phase I clinical trials (solid tumours and haematological malignancies) (Berenson et al, 2006; Lowndes et al, 2006) and is currently being

*Correspondence: Dr F Doñate, Attenuon, LLC, I0I I0 Sorrento Valley Road, Suite A, San Diego, CA 92121, USA;

E-mail: donate@attenuon.com

Revised 17 December 2007; accepted 7 January 2008; published online 5 February 2008 investigated in three phase II trials (melanoma, prostate and multiple myeloma). We have recently identified the copperdependent enzyme superoxide dismutase 1 (SOD1) as the main target for the antiproliferative activity of ATN-224 in endothelial and tumour cells (Juarez et al, 2006). Superoxide dismutase 1 is an abundant cytosolic enzyme that dismutates superoxide into hydrogen peroxide and molecular oxygen. The SOD1 activity in erythrocytes has been proposed as a biomarker for copper status in humans (Uauy et al, 1985; Milne, 1998).

Collectively, the data on TM and ATN-224 strongly support the notion that the biological activity of TM in vivo has a robust antiangiogenic component (Brewer et al, 2000; Pan et al, 2002, 2003a, b; Redman et al, 2003; Lowndes and Harris, 2004; Goodman et al, 2005; Juarez et al, 2006; Hassouneh et al, 2007). Although ATN-224 has also been shown to have antiproliferative and/or proapoptotic effects on tumour cells in vitro (Juarez et al, 2006), it is yet unclear whether sufficiently high concentrations of ATN-224 can be achieved and maintained in the tumour environment in vivo to elicit those responses.

Ceruloplasmin $(\mathrm{Cp})$ is a copper-containing oxidase, which is synthesised in the liver and circulated in blood. Cp contains approximately $95 \%$ of all copper in the blood; however, despite its high copper content, the role of $\mathrm{Cp}$ in copper transport is controversial. For example, targeted disruption of the $\mathrm{Cp}$ gene in mice does not alter copper absorption, transport or distribution 
(Meyer et al, 2001). Furthermore, patients with aceruloplasminaemia who lack a functional $\mathrm{Cp}$ have normal copper metabolism (Vassiliev et al, 2005). Although copper deficiency does not seem to directly affect the synthesis or secretion of $\mathrm{Cp}$ from the liver, the resulting apoprotein has a shorter half-life than that of the holo$\mathrm{Cp}$, and serum $\mathrm{Cp}$ measurements have been used to follow copper depletion: and pharmacokinetics (PK) and pharmacodynamics (PD) in clinical trials evaluating TM in cancer patients (Brewer et al, 2000; Redman et al, 2003; Lowndes and Harris, 2004; Goodman et al, 2005). However, the decrease in Cp levels may lag behind the onset of copper depletion, since apo-Cp is formed and degraded at a certain rate. Furthermore, we have observed that the inhibition of angiogenesis in mice by ATN-224 occurs before a measurable decrease in systemic copper is observed (Juarez et al, 2006). Thus, the identification of other biomarkers that may aid in the clinical development of ATN-224 is of interest.

\section{MATERIALS AND METHODS}

\section{Reagents}

ATN-224 (choline tetrathiomolybdate) was manufactured under cGMP using a proprietary manufacturing process with $>99 \%$ purity. The ATN-224 stocks $\left(50 \mathrm{mg} \mathrm{ml}^{-1}\right)$ were prepared in water, and aliquoted and frozen until use. ATN-224 was diluted to the desired concentration using phosphate-buffered saline (PBS) or media just prior to use. Blood was drawn from human volunteers into Vacutainer tubes (BD Biosciences, San Jose, CA, USA) containing citrate. Plasma and blood pellets were obtained by centrifugation. Blood cells were washed twice with PBS and analysed for SOD activity. Bovine SOD1 was acquired from Sigma (St Louis, MO, USA).

\section{Matrigel plug}

The Matrigel plug model was carried out as described before (Juarez et al, 2002). Briefly, cold Matrigel (BD) (500 $\mu \mathrm{l})$ was mixed with $800 \mathrm{ng} \mathrm{ml}^{-1}$ of FGF-2 or $300 \mathrm{ng} \mathrm{ml}^{-1}$ of VEGF and heparin $\left(50 \mu \mathrm{g} \mathrm{ml}^{-1}\right)$. Negative control plugs did not contain the proangiogenic factors. The Matrigel mixture was injected subcutaneously (s.c.) into 4- to 8-week-old female $\mathrm{BALB} / \mathrm{c}$ nude mice. Mice were treated by oral gavage either with distilled water or ATN-224. Animals were killed and the plugs recovered 5 days post plug injection. The haemoglobin levels in the plugs were determined using Drabkin's solution according to the manufacturers' instructions (Sigma).

\section{SOD assays}

Blood pellets were lysed by adding an equal volume of RIPA buffer. A 1:20 dilution of the lysate was carried out in Tris-buffered saline (1:10 for plasma samples) and protein concentration determined by the Bradford assay (Bio-Rad, Hercules, CA, USA). Thirty micrograms ( $60 \mu \mathrm{g}$ for plasma samples) were assayed as follows: SOD1 activity was determined by measuring the inhibition of reduction of the water-soluble tetrazolium salt, WST-1 (2-(4iodophenyl)-3-(4-nitrophenyl)-5-(2,4-disulfo-phenyl)-2H-tetrazolium, monosodium salt), which produces a water-soluble formazan dye upon reduction with a superoxide anion (Dojindo Molecular Technologies, Gaithersburg, MD, USA). Superoxide anion is generated by xanthine oxidase. Bovine SOD (Sigma), which has been shown to be equivalent to human SOD (Juarez et al, 2006), was used to generate a standard curve.

\section{Molybdenum levels}

The concentration of ATN-224 in blood was determined by measuring molybdenum (Mo) using ICP-MS. Cell extracts or whole tissues were sent to ERI (Vancouver, BC, Canada) for analysis. Cells and tissues were digested using $6 \mathrm{~N} \mathrm{HNO}_{3}$ to completely release all metals prior to analysis.

\section{Animal studies with mice}

A431 cells from ATCC were grown in Dulbecco's modified eagle media, $10 \%$ fetal bovine serum at $37^{\circ} \mathrm{C}$ in a humidified $5 \% \mathrm{CO}_{2}$ incubator. Two million cells were injected s.c. into female BALBc nude mice. When tumours reached $200-300 \mathrm{~mm}^{3}$, animals were randomised and treatment started. For some experiments, animals were treated daily with water, 50 or $150 \mathrm{mg} \mathrm{kg}^{-1}$ of ATN-224 by oral gavage. Animals were killed 10 days later, $3 \mathrm{~h}$ after the last dose of ATN-224. In other experiments, animals received water, or $100 \mathrm{mg} \mathrm{kg}^{-1}$ ATN-224 by oral gavage and were killed at different times. In both cases, tumours were isolated and blood was drawn. All animal procedures were performed according to approved protocols and in accordance with the recommendations for the proper care and use of laboratory animals. These studies were carried under the Institutional Animal Care and Use Committee (IACUC) from Perry Scientific (San Diego, CA, USA).

\section{Animal studies with bonnet macaques}

Subjects Subjects were three female and three male bonnet macaques (Macaca radiata), with a mean age of 12.9 years (s.e. $=0.84)$, corresponding to early to mid-adulthood in this species. Subjects were singly housed in the same temperature- and humidity-controlled room. Lighting was on a $12: 12 \mathrm{~h}$ light/dark cycle. Water and standard laboratory chow were available ad libitum.

ATN-224 administration Cages had a movable back by which subjects could be brought to the front of the cage for injection of ATN-224 (0.5 mg kg ${ }^{-1}$, s.c.). Injections began with a different monkey each day. Monkeys initially received ATN-224 for 22 consecutive days, followed by a drug holiday for 26 days. Drug injections then resumed for 33 out of the next 35 days and ATN-224 was given 15 min before lights went off at night.

Blood sampling Blood samples were always taken between 0900 and 1100 hours, and the order in which the subjects were sampled was systematically varied. The monkey was brought to the front of the cage by means of the movable cage back, and was given an injection of ketamine $\left(10-15 \mathrm{mg} \mathrm{kg}^{-1}\right.$, i.m.), immediately placed in a carrying cage, removed from the colony room and allowed to sit undisturbed for 10-15 min outside the veterinary treatment room a few feet away. The anaesthetised monkey was then taken from the carrying cage, the inner femoral area was shaved and disinfected, and approximately $10 \mathrm{ml}$ of blood was withdrawn from the femoral triangle. The blood was deposited in tubes with and without EDTA, and placed on ice. If insufficient blood was drawn from the femoral triangle, additional blood was collected from the cephalic vein. All animal procedures were performed according to approved protocols and in accordance with the recommendations for the proper care and use of laboratory animals. These studies were approved by the IACUC from SUNY Downstate Medical Center.

EPC quantitation Mononuclear cells were harvested from peripheral blood samples using Ficoll-Hypaque (Sigma) densitygradient centrifugation, followed by exposure of separated cells to a red blood cell lysis buffer (Roche Applied Science, Indianapolis, IN, USA). Direct immunofluorescence using combinations of monoclonal antibodies including anti-CD31-FITC (BD Biosciences); anti-CD133-PE (Miltenyi Biotec, Auburn, CA, USA) and antiCD45-PE/Cy5 (eBioscience, San Diego, CA, USA) was performed as previously described (Zhang et al, 2005). Cells were analysed by 
three-colour flow cytometry using a FACSort flow cytometer (BD Biosciences) using the CellQuest software program (BD Immunocytometry Systems, San Diego, CA, USA) with appropriate compensation.
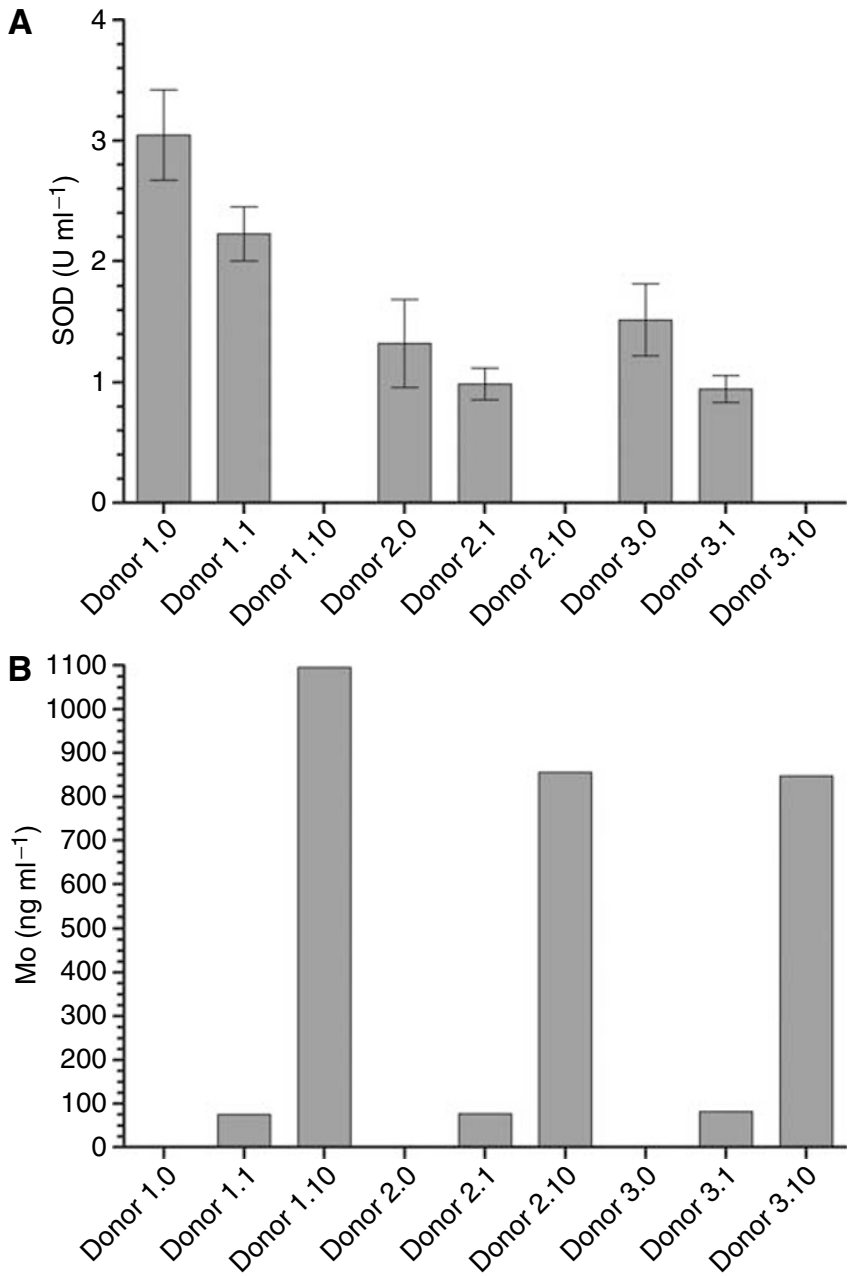

Figure I ATN-224 inhibits SOD activity in blood cells. Anticoagulated blood from three volunteers was incubated with ATN-224 (0, I and $10 \mu \mathrm{M})$ for $5.5 \mathrm{~h}$ at $37^{\circ} \mathrm{C}$, and plasma and blood pellets were prepared by centrifugation. (A) ATN-224 inhibits the SOD activity in blood pellets. The SOD activity was measured in blood pellets as described in Materials and Methods. (B) Levels of molybdenum are in agreement with SOD activity measurements. Molybdenum content was measured using ICP-MS for the same samples analysed for SOD activity.

Figure 2 Inhibition of the SOD activity in human and mouse blood cells by ATN-224. (A) ATN-224 inhibits the SOD activity in human blood cells. Human anticoagulated blood from volunteers was incubated with different concentrations of ATN-224 overnight, and intracellular SOD activity was measured as described in Materials and Methods. Three different experiments are shown. ATN-224 inhibited SOD activity with an $1 C_{50}=2.91 \pm 0.48 \mu \mathrm{m}$. (B) ATN-224 inhibits the SOD activity of mouse blood cells. Mouse anticoagulated blood was incubated with different concentrations of ATN-224 overnight, and intracellular SOD activity was measured as described in Materials and Methods. Three different experiments are shown. ATN-224 inhibited SOD activity with an $I C_{50}=3.5 \mathrm{I} \pm 1.7 \mu \mathrm{M}$. (C) The IC 50 of ATN-224 for purified SODI activity increases in the presence of human plasma. Purified bovine SODI $\left(5 \cup \mathrm{ml}^{-1}\right)$ was incubated with human plasma overnight, and SOD activity was measured as described in Materials and Methods. The SOD activity measured in human plasma is negligible. ATN-224 inhibited SOD activity with an $\mathrm{IC}_{50}=2.03 \mu \mathrm{M}$.
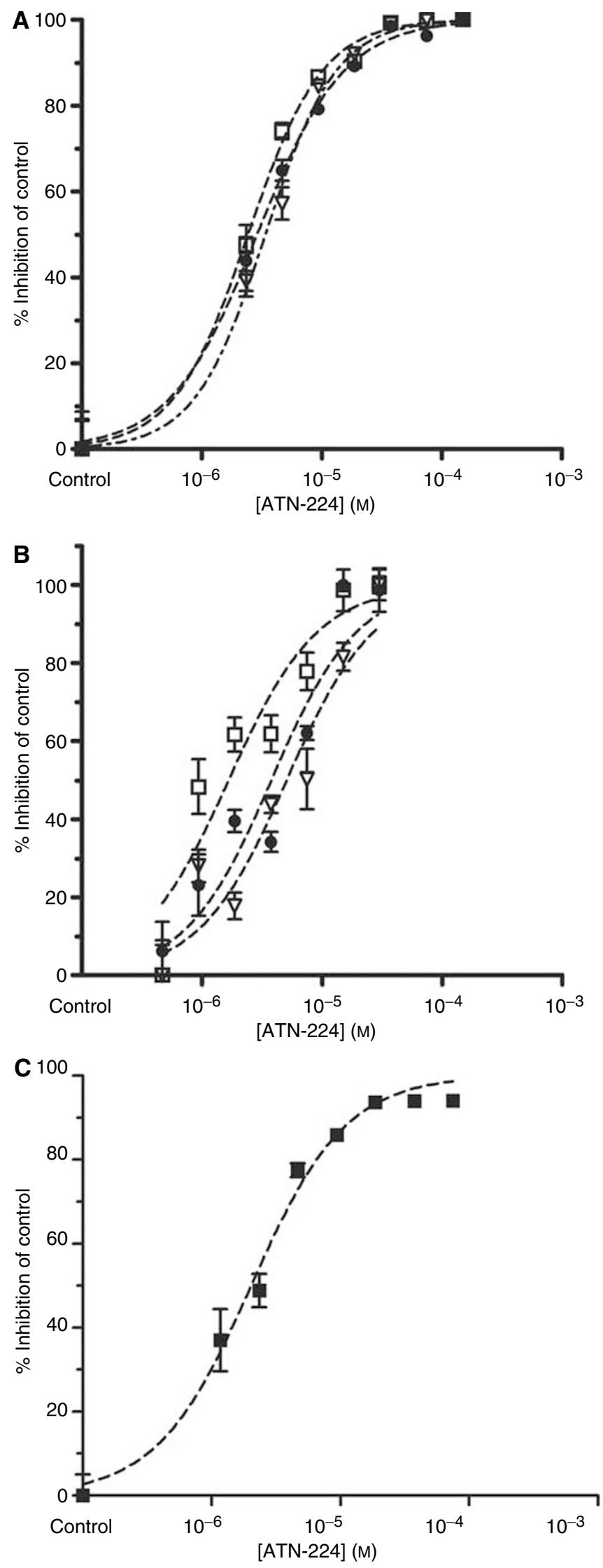


\section{Statistical analysis}

GraphPad software was used for all statistical analysis. Data are presented as mean \pm s.d. Data were analysed using unpaired, twotailed $t$-tests when comparing two variables. Analysis of variance with Tukey's posttest was used to compare data in experiments where more than two variables were compared simultaneously.

\section{RESULTS}

As ATN-224 treatment inhibits SOD activity in endothelial and tumour cells (Juarez et al, 2006), the effect of ATN-224 on SOD activity in blood cells was tested. Superoxide dismutase 3 is also a copper-dependent enzyme, which is bound to the extracellular matrix in mammalian tissues (Nozik-Grayck et al, 2005). It is mainly produced by vascular smooth muscle cells and retained in the vascular wall, and therefore mainly absent in erythrocytes and other blood cells (Nozik-Grayck et al, 2005). Superoxide dismutase 3 is mainly responsible for the SOD activity found in plasma and serum (Nozik-Grayck et al, 2005; Tasaki et al, 2006), and decreased copper levels inhibit its activity in rats (Johnson et al, 2005). Superoxide dismutase 3 activity in human plasma is low, but increases upon treatment with heparin (Tasaki et al, 2006). Blood from laboratory personnel who had volunteered for venipuncture was drawn and samples were incubated with ATN-224 for $5.5 \mathrm{~h}$ at $37^{\circ} \mathrm{C}$. Plasma and blood pellets were prepared after incubation with ATN-224 and SOD activity and molybdenum (Mo) levels were determined. The levels of SOD activity in plasma from human volunteers were below the detection limits of our assay (data not shown) in agreement with the low levels of SOD3 that have been reported in plasma of humans (Tasaki et al, 2006). Figure 1A shows that ATN-224 inhibited SOD activity in blood cell pellets in a dose-dependent manner in agreement with the levels of Mo (representing ATN-224) associated with the cells (Figure 1B). ATN-224 inhibits SOD1 by removing copper from the active site (Juarez et al, 2006). As expected, it does not inhibit Escherichia coli SOD (data not shown), a manganese-containing enzyme. Furthermore, the majority of the SOD activity in blood cell lysates comes from SOD1 and not SOD2: as a SOD1-specific inhibitor (KCN) decreased the measured total SOD activity to background levels (data not shown). Thus, despite the fact that we used whole cell extracts, we only observed SOD1 in this assay. Next, the $\mathrm{IC}_{50}$ for the inhibition of SOD activity by ATN-224 in human and mouse blood cells was measured (Figures $2 \mathrm{~A}$ and $\mathrm{B}$ ) according to the protocol used in Figure 1, except that blood samples were incubated with ATN-224 overnight. The determined $\mathrm{IC}_{50}$ was approximately $3 \mu \mathrm{M}$ for human and mouse blood cell SOD1. The $\mathrm{IC}_{50}$ for inhibition of purified SOD1 is $300 \mathrm{~nm}$ (Juarez et al, 2006), which is $\sim 10$-fold lower than the $\mathrm{IC}_{50}$ for SOD1 in blood cells. In the presence of albumin and presumably copper, ATN-224 forms a complex that is inactive in an endothelial proliferation assay (Juarez et al, 2006), and we suspected that the formation of that complex in blood could explain the higher $\mathrm{IC}_{50}$ against blood cells. This possible matrix effect in blood was tested by assaying purified bovine SOD1 in fresh human plasma instead of buffer and determining an $\mathrm{IC}_{50}$ for ATN-224 inhibition. The $\mathrm{IC}_{50}$ under these conditions was $\sim 2 \mu \mathrm{M}$ (Figure $2 \mathrm{C}$ ), approximately seven-fold higher than that needed to inhibit purified SOD1, suggesting that a proportion of the ATN-224 in plasma is inactivated by forming a tripartite complex with albumin and copper. The data presented thus far supports the notion that ATN-224 inhibits SOD activity in blood cells and that the dose at which that occurs may reflect the level of active compound.

Both in tumour models (Pan et al, 2002, 2003a, b; Hassouneh et $a l, 2007)$ and in in vivo angiogenesis models, such as the Matrigel plug model (Juarez et al, 2006), ATN-224 has a strong antiangiogenic activity, and we wished to establish a relationship between the dose needed to inhibit angiogenesis and that needed
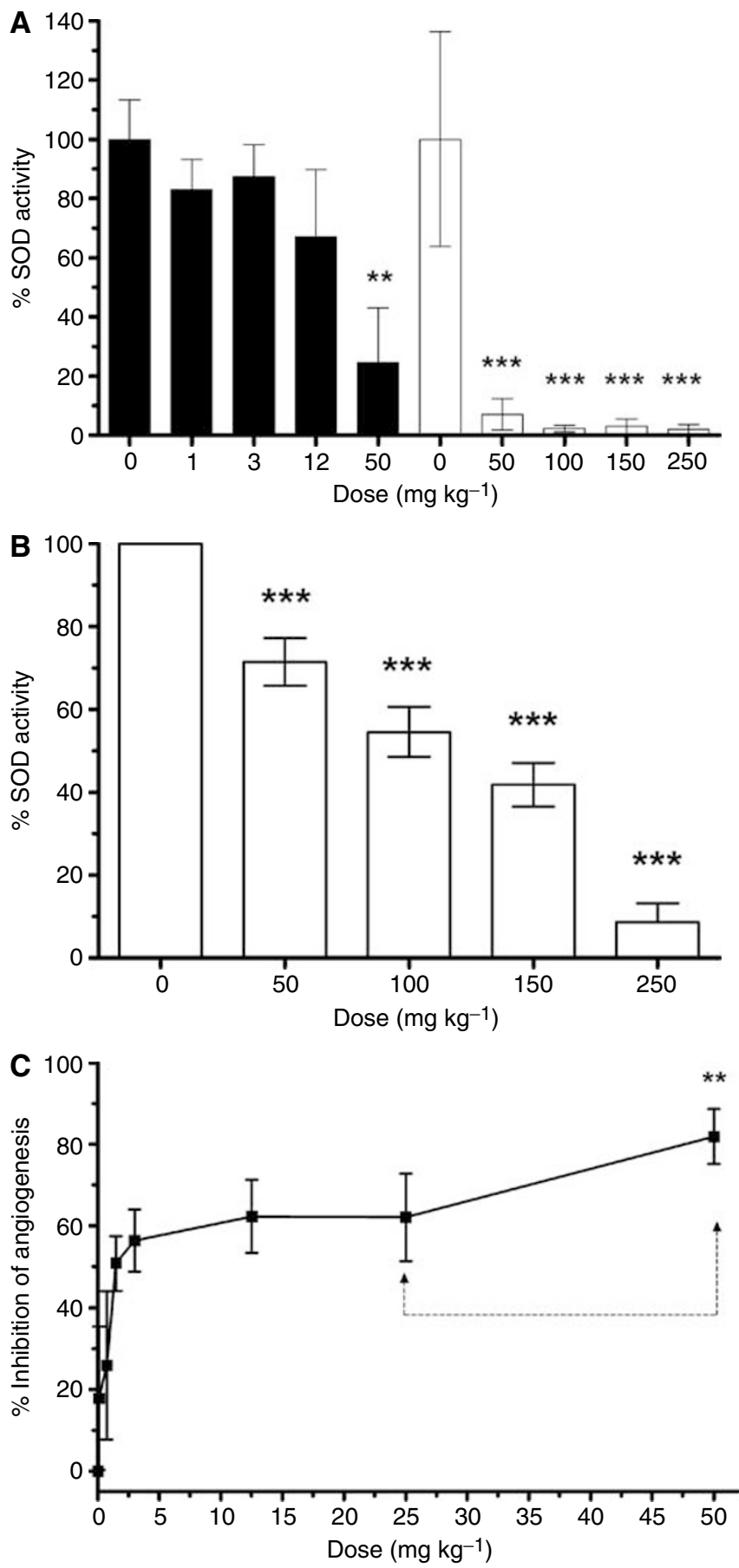

Figure 3 Plasma extracellular SOD, blood cell SOD and angiogenesis (Matrigel plug model) are inhibited in mice at different doses of ATN-224. $(\mathbf{A}$ and $\mathbf{B})$ The ATN-224 dosing inhibits the SOD activity in plasma (A) and blood cells (B). Blood was collected after 5 days dosing with ATN-224, centrifuged and plasma and cell pellets were isolated. Superoxide dismutase activity was measured as described in Materials and Methods. In (A), two titrations (black and white bars) were carried out, and the 0 and $50 \mathrm{mg} \mathrm{kg}^{-1}$ data points are included in the second titration for comparison purposes with the first titration. (C) ATN-224 inhibits angiogenesis in the Matrigel plug model in a dose-dependent manner. Mice were treated daily for 5 days by oral gavage with the indicated amounts of ATN-224 or vehicle control. Angiogenesis was measured by measuring haemoglobin levels as indicated in the Materials and Methods section; ${ }^{*} P<0.01$, **** $P<0.00$ I (t-test). 
to inhibit SOD activity in blood cells. Mice were dosed daily by gavage with different doses of ATN-224 for 5 days and SOD activity was determined in plasma and blood pellets at the end of the experiment (Figures $3 \mathrm{~A}$ and $\mathrm{B}$ ). In contrast to our results with human plasma (see above), mouse plasma SOD activity was easily

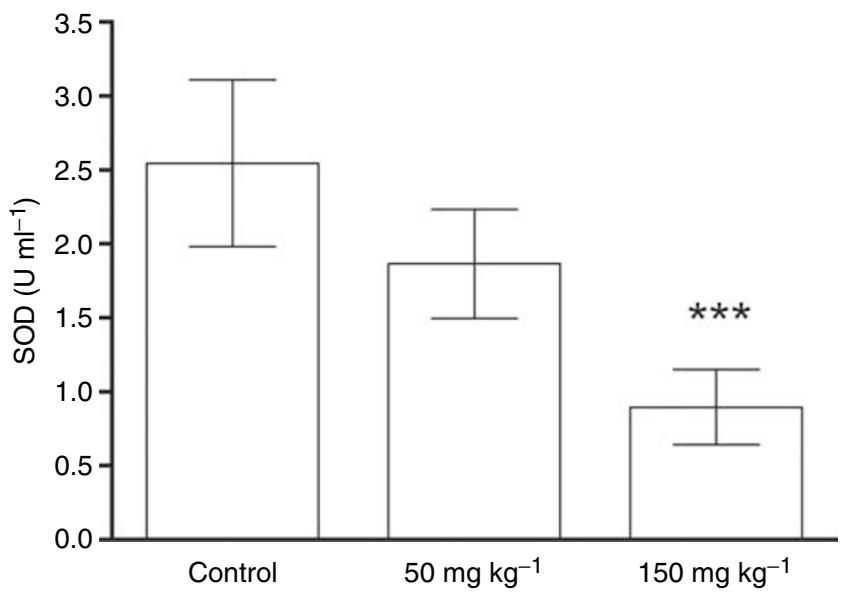

Figure 4 Inhibition of tumour cell SOD by ATN-224 in an A43। xenograft model. Tumour-bearing mice were treated daily for 10 days by oral gavage with the indicated amounts of ATN-224 or vehicle control. Tumours were minced and lysed. Superoxide dismutase I activity was measured as described in Materials and Methods; ${ }^{* * *} P<0.00$ I (t-test). detectable and ATN-224 treatment inhibited SOD activity indicating that SOD3, primarily responsible for SOD activity in plasma, can also be inhibited by ATN-224. In a second experiment, a dose titration for ATN-224 in the mouse Matrigel plug model was carried out (Figure 3C). The $\mathrm{IC}_{50}$ was determined to be approximately $1.50-3 \mathrm{mg} \mathrm{kg}^{-1}$ and a dose of $50 \mathrm{mg} \mathrm{kg}^{-1}$ produced an inhibition of $82 \%$ in the Matrigel plug assay. The $50 \mathrm{mg} \mathrm{kg}^{-1}$ dose is similar to a dose used before to optimally inhibit tumour growth and angiogenesis in tumour-bearing mice $\left(35-50 \mathrm{mg} \mathrm{kg}^{-1}\right.$ $\mathrm{TM}$, which is equivalent to $59-85 \mathrm{mg} \mathrm{kg}^{-1} \mathrm{ATN}-224$ on a molar basis) (Pan et al, 2002, 2003a, b; Hassouneh et al, 2007). Doses of 50 and $250 \mathrm{mg} \mathrm{kg}^{-1}$ were needed to completely inhibit SOD activity in plasma and blood pellets, respectively, suggesting that inhibition of SOD activity occurs at doses at which angiogenesis is maximally inhibited.

The ATN-224 treatment also inhibited SOD activity in A431 tumours grown s.c. in mice (Figure 4). Unlike human tumours, experimental tumours grown s.c. in mice lack significant stroma, and therefore, the majority of the tumour mass is made up of tumour cells per se. Tumour-bearing mice were treated with buffer control, 50 or $150 \mathrm{mg} \mathrm{kg}^{-1}$ of ATN-224 daily by oral gavage for 10 days. The $50 \mathrm{mg} \mathrm{kg}^{-1}$ dose is similar to a dose used before to optimally inhibit tumour growth and angiogenesis in tumourbearing mice $\left(35-50 \mathrm{mg} \mathrm{kg}^{-1} \mathrm{TM}\right.$, which is equivalent to $59-$ $85 \mathrm{mg} \mathrm{kg}^{-1}$ ATN-224 on a molar basis) (Pan et al, 2002, 2003a, b; Hassouneh et al, 2007). At the end of the treatment, the mice were killed, and the tumours were removed and lysed. The SOD activity in controls and ATN-224-treated mice was measured. The SOD assays were carried out using either 30 or $60 \mu \mathrm{g}$ of total extracted protein and the SOD activity $\left(\mathrm{U} \mathrm{ml}^{-1}\right)$ calculated from a standard
A
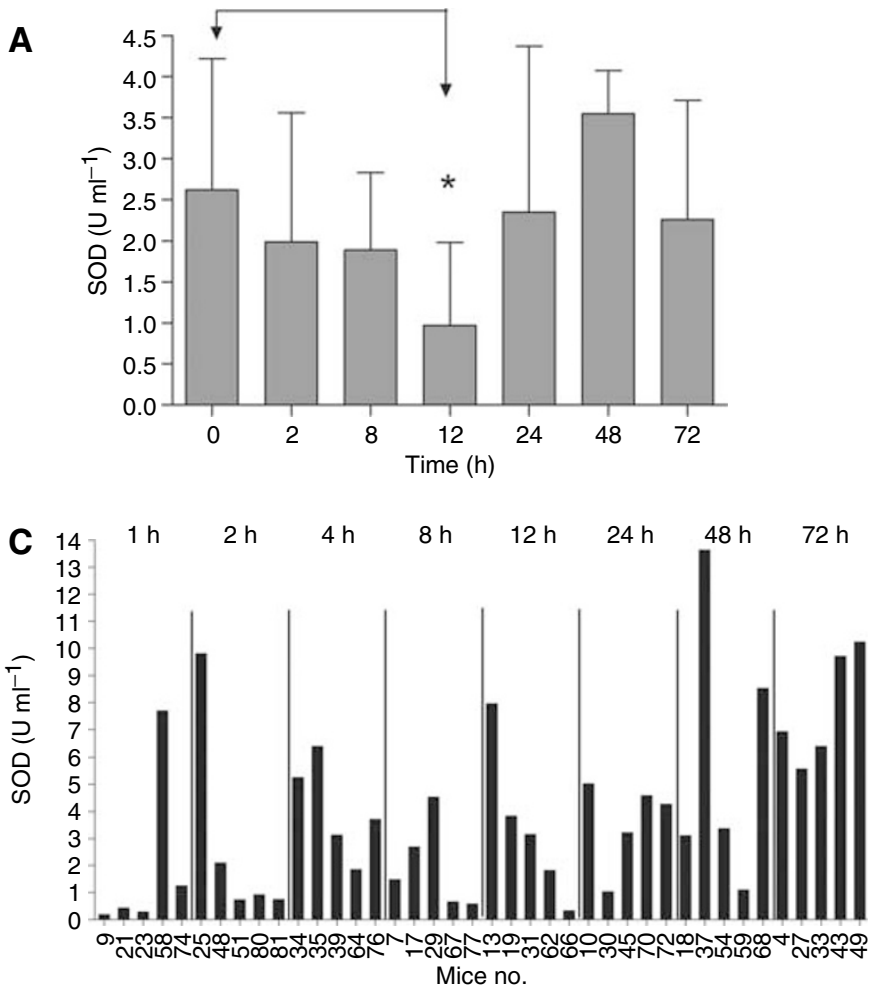

B

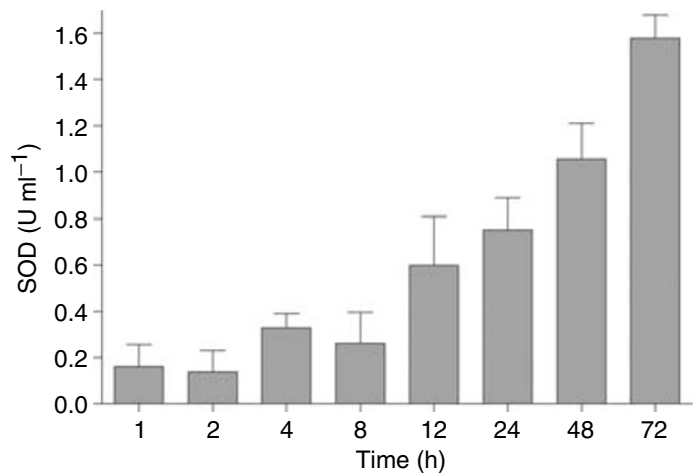

D

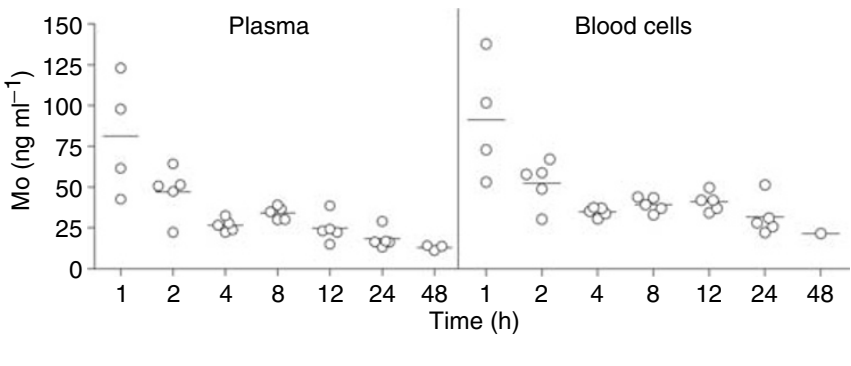

Figure 5 Inhibition of tumour cell SOD after a single dose of ATN-224 in A43। tumour-bearing mice. Mice were given a $100 \mathrm{mg} \mathrm{kg}{ }^{-1}$ dose by oral gavage of ATN-224. At the indicated times, mice were killed and blood and tumours collected. (A) A single dose of ATN-224 inhibits the SOD activity in tumours in a time-dependent manner. Mice were killed at the indicated times and tumours resected, minced and lysed. Superoxide dismutase I activity was measured as described in Materials and Methods. (B) A single dose of ATN-224 inhibits the SOD activity in plasma in a time-dependent manner. (C) A single dose of ATN-224 inhibits the SOD activity in blood cells in a time-dependent manner; $* P<0.05$ (t-test). (D) Levels of molybdenum agree with SOD activity measurements. Molybdenum content in plasma and blood cells was measured using ICP-MS. 


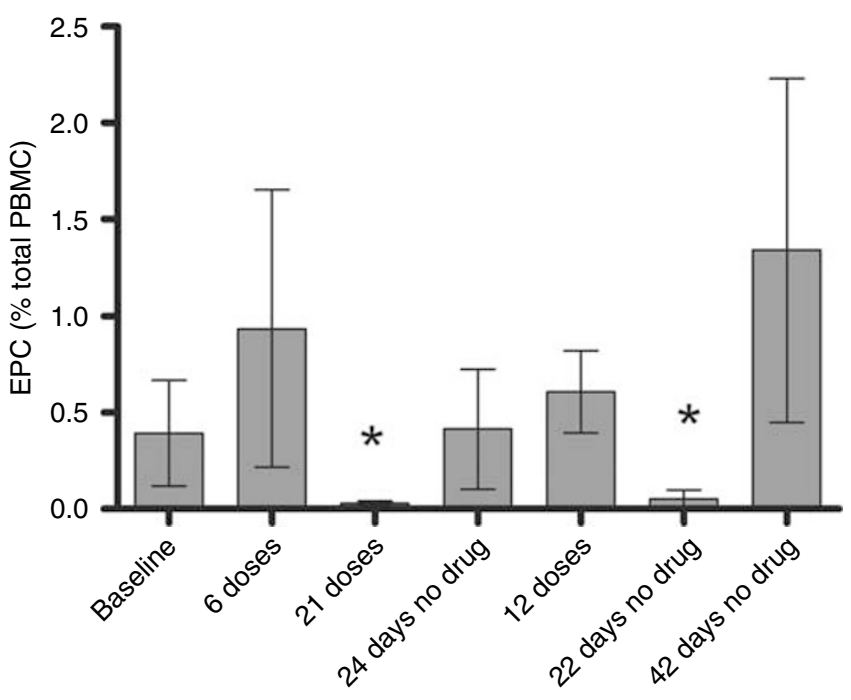

Figure 6 ATN-224 treatment lowers CECs and EPCs in monkeys. Six bonnet macaques were treated daily with ATN-224 $\left(0.5 \mathrm{mg} \mathrm{kg}^{-1}\right.$, s.c.) for 22 days followed by a 26-day drug holiday and 33 more days of treatment. The percentages of CD3I + /CDI33 + /CD45 weak (EPCs) populations measured by flow cytometry are shown for each animal at the indicated time points on the $X$ axis; ${ }^{*} P=0.021$.

curve generated using purified SOD as a standard. The $50 \mathrm{mg} \mathrm{kg}^{-1}$ dose of ATN-224 resulted in an approximately $26 \%$ reduction of the SOD activity, whereas the $150 \mathrm{mg} \mathrm{kg}^{-1}$ dose inhibited SOD by $65 \%(P<0.001)$ when compared with control mice. Similarly, when A549 tumour-bearing mice were treated for 10 days with $100 \mathrm{mg} \mathrm{kg}^{-1}$ daily of ATN-224, the SOD activity in the tumour was inhibited by $\sim 80 \%$ (data not shown). Next, we wished to investigate the kinetics of the SOD inactivation in tumours after a single dose of ATN-224 (100 mg kg-1) in A431 tumour-bearing mice. The results showed a significant inhibition of the SOD activity in the tumour, which was maximal at $12 \mathrm{~h}$ and returned to normal levels $24 \mathrm{~h}$ after treatment (Figure 5A). Similar results were observed in a second experiment (data not shown) in which the SOD activity and molybdenum levels in plasma and blood pellets were also measured (Figures 5B-D). As expected, the SOD activity in plasma is almost completely inhibited, but it appears to take longer to recover than in the tumour (Figure 5B). The SOD activity in the blood pellet is also inhibited (Figure 5C), but the level of inhibition is significantly variable among mice within the same time point. This variability is not due to differences in the level of drug as the concentration of Mo does not change significantly within mice in the same group (Figure 5D). This variability is not observed in mice that have been treated for 5 or 10 days with ATN224. Altogether, these data indicate that SOD1 inhibition can be detected even after a single dose of ATN-224 in the tumour, plasma and blood cells, much earlier than the detection of decreases in $\mathrm{Cp}$ are observed in mice or humans (Lowndes and Harris, 2004; Goodman et al, 2005). This suggests that the SOD inhibition in blood and blood cells is a faster and more sensitive read-out of the biological activity of ATN-224. This is also consistent with our earlier observation that inhibition of angiogenesis takes place before systemic copper depletion is achieved (Juarez et al, 2006).

The levels of circulating endothelial cells (CECs) and endothelial progenitor cells (EPCs) increase in several pathological conditions, including cancer (Bertolini et al, 2006). Preclinical and clinical studies (Shaked et al, 2005; Zhang et al, 2005; Bertolini et al, 2006; Bhatt et al, 2007) have shown a correlation between CEC and EPC numbers and the antiangiogenic activity of different drugs, and thus, measurements of CEC and/or EPC have been proposed as biomarkers for monitoring antiangiogenic drug activity (Bertolini et al, 2006; Bhatt et al, 2007). To test the effect of ATN-224 on EPCs, different cell surface markers were first evaluated for the proper identification of EPCs using bonnet macaques as a model that would identify markers that could be translated into humans. Thus, EPCs were identified as CD31 + /CD133 + /CD45 weak and measured in six bonnet macaques that were treated daily with ATN-224 (0.5 $\mathrm{mg} \mathrm{kg}^{-1}$, s.c.) for 22 days followed by a 26 -day drug holiday, and then 33 more days of treatment. The dose was chosen based on bioavailability studies that showed bioequivalency of that dose with a dose of $25 \mathrm{mg} \mathrm{kg}^{-1}$ in mice given orally (data not shown). This dose was thought to be nontoxic, but sufficiently high to inhibit angiogenesis. The monkeys readily adapted to the experimental procedure, and exhibited no distress throughout. No behavioural changes (e.g., activity or interactional behaviours) were apparent across the course of the experiment, although mean body weight of the monkeys decreased by $8 \%$ by the end of the initial period of drug administration $(P=0.012)$. By the end of the drug holiday, mean body weights had recovered to $95 \%$ of baseline values. It was thought that the drug could be interfering with the monkeys' evening feeding and during the second round of drug administration, ATN-224 was given $15 \mathrm{~min}$ before the colony room lights went off instead of the $30-90 \mathrm{~min}$ of the first round. Interestingly, mean body weights did not change during the course of the second round of drug administration. All animals developed mild alopecia during the first administration of ATN-224. This was partially resolved during the drug holiday and second round of ATN-224. The levels of EPCs increased initially at day 6 in five out of the six subjects, and then decreased to $7 \%$ of baseline at day 21 (Figure 6). The EPC levels rebounded to normal levels once treatment was discontinued and dropped again after treatment was reinstated. All other parameters measured, for example, red and white blood cell counts, platelets and haemoglobin levels were not affected by treatment (data not shown). Although we did not measure blood cell SOD in the macaque study, the recently completed phase I study with ATN-224 (Lowndes et al, 2006) indicated that substantial and maintained inhibition of blood cell SOD was associated with haematologic toxicities. As we observed significant depletion of EPCs in the macaques at a dose of ATN224 that does not affect haematologic parameters, it is unlikely that we had significant inhibition of blood cell SOD in that study, further supporting the hypothesis that doses at which red blood cell (RBC) SOD activity is inhibited exceed the threshold required for antiangiogenic activity. Therefore, measuring EPCs in patients receiving ATN-224 may be a useful biomarker of antiangiogenic activity.

\section{DISCUSSION}

The need for biomarkers in clinical development is clear and even more important for noncytotoxic agents, which often do not cause objective responses (Bhatt et al, 2007). Biomarkers are useful in managing dosing and toxicity, monitoring clinical benefit and/or in selecting patients more likely to benefit from the drug being tested. Ideally, besides being informative, biomarker assays should also be as minimally invasive as possible and preferably use tissue samples that are readily accessible in patients. Here, we report the evaluation of two possible biomarkers for ATN-224, the SOD activity in blood and EPC levels also in blood that will be measured during the clinical development of ATN-224. Both biomarker assays are minimally invasive, requiring only simple blood samples with minimal processing, and can be utilised to monitor biological activity of ATN-224 and to manage dosing. The SOD activity can be measured in blood pellets and tumour lysates, and is quickly inhibited upon ATN-224 dosing. The PK of ATN-224 is followed by tracking Mo in plasma (Berenson et al, 2006; Lowndes et al, 2006). This approach, however, does not distinguish the active compound from its metabolites. Despite our best efforts, no methodology has 
been found to track the active compound. An alternative approach could be to follow a pharmacodynamic marker in blood that may be a read-out of active drug exposure. The SOD activity in blood pellets of mice treated with ATN-224 reflects the levels of 'active' compound, and the changes are observed very early after the initiation of treatment in contrast to changes in $\mathrm{Cp}$, which take weeks of TM treatment to be observed (Brewer et al, 2000; Pan et al, 2002, 2003a, b; Redman et al, 2003; Goodman et al, 2005; Hassouneh et al, 2007). Thus, changes in the SOD activity in blood may provide a sensitive barometer of drug exposure in animals and humans.

The data in mice indicate that the concentrations needed to inhibit the SOD activity in blood pellets $\left(\mathrm{ED}_{50} \sim 100-150 \mathrm{mg} \mathrm{kg}^{-1}\right.$, equivalent to $\sim 8-12 \mathrm{mg} \mathrm{kg}^{-1}$ in humans) are higher than the doses that have been used in clinical trials $\left(\sim 3 \mathrm{mg} \mathrm{kg}^{-1}\right.$ of TM, equivalent to $5 \mathrm{mg} \mathrm{kg}^{-1}$ of ATN-224) (Brewer et al, 2000; Redman et al, 2003), implying that the SOD inhibition in human blood may not occur upon ATN-224 dosing. On the other hand, copper deficiency in humans has been shown to correlate with decreased SOD1 activity in RBC (Uauy et al, 1985; Milne, 1998), suggesting that ATN-224, which lowers levels of systemic copper in humans, should also inhibit SOD1. There are several possible reasons to explain this discrepancy between humans and mice. For instance, there may be differences among species as to the doses needed to inhibit the SOD1 activity in blood cells, and, importantly, we have shown that ATN-224 accumulates in cells (Juarez et al, 2006). This suggests that longer treatments than those used in this study may lower the threshold of ATN-224 needed for inhibiting blood cell SOD1. Indeed, data from a phase I trial showed a profound and persistent inhibition of SOD1 in blood pellets in patients treated at several ATN-224 doses below and at the maximal tolerated dose (Lowndes et al, 2006).

Inhibition of angiogenesis, as determined in the Matrigel plug model, occurs at lower doses than those needed for the SOD1 inhibition in blood pellets of mice. This suggests that the SOD1 inhibition in blood pellets will be indicative of antiangiogenic activity, since when a dose capable of inhibiting blood cell SOD1 is achieved the threshold for antiangiogenic activity would have been crossed. This is confirmed by the fact that at doses where SOD1 activity is beginning to be inhibited, there is already a significant effect observed on EPC levels, a biomarker for angiogenesis. In contrast, a lack of SOD1 inhibition would be noninformative with respect to the inhibition of angiogenesis. The relationship between the SOD1 inhibition in blood cells and antiangiogenic activity in humans has been studied in a phase I trial (Lowndes et al, 2006).

It has been shown that ATN-224 has antiproliferative and/or proapoptotic effects on tumour cells in vitro but only when SOD1 activity was inhibited almost $100 \%$ (Juarez et al, 2006). Inhibition of the SOD activity in tumour-bearing animals treated with ATN-224 for 10 days was $65-80 \%$ at a concentration that is approximately two- to three-fold higher than the concentrations reported for antitumour activity in mice, suggesting that ATN-224 may not be exerting a significant direct effect in tumour cells, at least in a xenograft model. Alternatively, it is possible that SOD1 inhibition is not homogeneous throughout the tumour and that areas exist in which SOD1 inhibition is complete and direct antitumour activity may occur. Currently, a method for measuring the SOD activity in fixed tissue is being developed to address this question. Finally, a xenografted tumour in a mouse, which is essentially a sphere of tumour cells, may not accurately reflect the situation with respect to human cancer, whether significant stromal components also exist in addition to the tumour cells themselves. Thus, our data only provide a rationale for studying the relationship of SOD1 inhibition to the inhibition of tumour growth in humans but may not accurately predict a correlation or lack thereof.

Endothelial progenitor cells have recently been used in several animal studies and clinical trials to follow the activity of a variety of antiangiogenic agents (Shaked et al, 2005; Zhang et al, 2005; Bertolini et al, 2006; Bhatt et al, 2007), and this technique continues to gain confirmation and acceptance as a promising biomarker for the inhibition of angiogenesis. On the basis of the results and rationale presented herein, SOD1 inhibition and depletion of EPCs/CECs, as well as Cp levels, have been evaluated for their ability to follow active drug and drug PD in a recently completed phase I clinical trial in patients with advanced solid cancer (Lowndes et al, 2006), and a paper describing these studies has now been submitted for publication.

\section{REFERENCES}

Berenson JR, Boccia RV, Bashey A, Levine AM, Koc ON, Callahan JA, Mazar AP, Reich SD (2006) Phase I study of the [Cu, $\mathrm{Zn}]$ superoxide dismutase (SOD1) inhibitor ATN-224 (Bis-choline tetrathiomolybdate) in patients (pts) with advanced hematologic malignancies. Blood (ASH Annual Meeting Abstracts) 108. Abstracts 2593

Bertolini F, Shaked Y, Mancuso P, Kerbel RS (2006) The multifaceted circulating endothelial cell in cancer: towards marker and target identification. Nat Rev Cancer 6: 835-845

Bhatt RS, Seth P, Sukhatme VP (2007) Biomarkers for monitoring antiangiogenic therapy. Clin Cancer Res 15: 777s-780s

Brewer GJ, Dick RD, Grover DK, LeClaire V, Tseng M, Wicha M, Pienta K, Redman BG, Jahan T, Sondak VK, Strawderman M, LeCarpentier G, Merajver SD (2000) Treatment of metastatic cancer with tetrathiomolybdate, an anticopper, antiangiogenic agent: phase I study. Clin Cancer Res 6: $1-10$

Carmeliet P (2005) Angiogenesis in life, disease and medicine. Nature 438: 932-936

Doñate F (2005) Anti-angiogenic therapy in cancer. Drugs Future 30: 695-707

Ferrara N, Kerbel RS (2005) Angiogenesis as a therapeutic target. Nature 438: $967-974$

Goodman VL, Brewer GJ, Merajver SD (2005) Control of copper status for cancer therapy. Curr Cancer Drug Targets 5: 543-549

Hassouneh B, Islam M, Nagel T, Pan Q, Merajver SD, Teknos TN (2007) Tetrathiomolybdate promotes tumor necrosis and prevents distant metastases by suppressing angiogenesis in head and neck cancer. Mol Cancer Ther 6: 1039-1045

Johnson WT, Johnson LA, Lukaski HC (2005) Serum superoxide dismutase 3 (extracellular superoxide dismutase) activity is a sensitive indicator of $\mathrm{Cu}$ status in rats. J Nutr Biochem 11: 682-692

Juarez JC, Betancourt Jr O, Pirie-Shepherd SR, Guan X, Price ML, Shaw DE, Mazar AP, Doñate F (2006) Copper binding by tetrathiomolybdate attenuates angiogenesis and tumor cell proliferation through the inhibition of superoxide dismutase 1. Clin Cancer Res 12: $4974-4982$

Juarez JC, Guan X, Shipulina NV, Plunkett ML, Parry GC, Shaw DE, Zhang JC, Rabbani SA, McCrae KR, Mazar AP, Morgan WT, Doñate F (2002) Histidine-proline-rich glycoprotein has potent antiangiogenic activity mediated through the histidine-proline-rich domain. Cancer Res 62: $5344-5350$

Lowndes SA, Adams A, Timms A, Middleton M, Hayward C, Reich SD, Mazar AP, Harris AL (2006) Phase I study of ATN-224 in patients (pts) with advanced solid tumours. 2006 ASCO Annual Meeting Proceedings Part I 24, No. $18 \mathrm{~S}$

Lowndes SA, Harris AL (2004) Copper chelation as an antiangiogenic therapy. Oncol Res 14: 529-539

Meyer LA, Durley AP, Prohaska JR, Harris ZL (2001) Copper transport and metabolism are normal in aceruloplasminemic mice. J Biol Chem 276: $36857-36861$

Milne DB (1998) Copper intake and assessment of copper status. Am J Clin Nutr 67(Suppl 5): 1041S-1045S

Nozik-Grayck E, Suliman HB, Piantadosi CA (2005) Extracellular superoxide dismutase. Int J Biochem Cell Biol 12: 2466-2471 
Pan Q, Bao LW, Kleer CG, Brewer GJ, Merajver SD (2003a) Antiangiogenic tetrathiomolybdate enhances the efficacy of doxorubicin against breast carcinoma. Mol Cancer Ther 2: 617-622

Pan Q, Bao LW, Merajver SD (2003b) Tetrathiomolybdate inhibits angiogenesis and metastasis through suppression of the NFkB signaling cascade. Mol Cancer Res 1: $701-706$

Pan Q, Kleer CG, van Golen KL, Irani J, Bottema KM, Bias C, De Carvalho M, Mesri EA, Robins DM, Dick RD, Brewer GJ, Merajver SD (2002) Copper deficiency induced by tetrathiomolybdate suppresses tumor growth and angiogenesis. Cancer Res 62: 4854-4859

Redman BG, Esper P, Pan Q, Dunn RL, Hussain HK, Chenevert T, Brewer GJ, Merajver SD (2003) Phase II trial of tetrathiomolybdate in patients with advanced kidney cancer. Clin Cancer Res 9: 1666-1672

Shaked Y, Bertolini F, Man S, Rogers MS, Cervi D, Foutz T, Rawn K, Voskas D, Dumont DJ, Ben-David Y, Lawler J, Henkin J, Huber J, Hicklin DJ, D'Amato RJ, Kerbel RS (2005) Genetic heterogeneity of the vasculogenic phenotype parallels angiogenesis; implications for cellular surrogate marker analysis of antiangiogenesis. Cancer Cell 1: 101-111

Tasaki H, Yamashita K, Tsutsui M, Kamezaki F, Kubara T, Tanaka S, Sasaguri Y, Adachi T, Nakashima Y (2006) Heparin-released extracellular superoxide dismutase is reduced in patients with coronary artery atherosclerosis. Atherosclerosis 187: $131-138$

Uauy R, Castillo-Duran C, Fisberg M, Fernandez N, Valenzuela A (1985) Red cell superoxide dismutase activity as an index of human copper nutrition. J Nutr 115: 1650 - 1655

Vassiliev V, Harris ZL, Zatta P (2005) Ceruloplasmin in neurodegenerative diseases. Brain Res Brain Res Rev 49: 633-640

Zhang H, Vakil V, Braunstein M, Smith EL, Maroney J, Chen L, Dai K, Berenson JR, Hussain MM, Klueppelberg U, Norin AJ, Akman HO, Ozçelik T, Batuman OA (2005) Circulating endothelial progenitor cells in multiple myeloma: implications and significance. Blood 105: $3286-3294$ 